\title{
Representações sociais do cuidado em saúde por mulheres quilombolas ${ }^{a}$
}

\author{
Social representations of health care by quilombola women \\ Representaciones sociales de la atención de salud de mujeres quilombola
}

Ingrid Fabiane Santos da Silva ${ }^{1}$ (D) Ivaneide Leal Ataíde Rodrigues ${ }^{2}$ (D)

Laura Maria Vidal Nogueira ${ }^{2}$ (C)

Hilton Pereira da Silva ${ }^{3}$ (a)

laci Proença Palmeira ${ }^{2}$ (1)

1. Universidade Federal do Rio de Janeiro, Programa de Pós-Graduação em Enfermagem. Rio de Janeiro, RJ, Brasil.

2. Universidade do Estado do Pará, Programa de Pós-Graduação em Enfermagem. Belém, PA, Brasil.

3. Universidade Federal do Pará, Programa de Pós-Graduação em Antropologia. Belém, PA, Brasil.

\section{Resumo}

Objetivo: Analisar as representações sociais de mulheres quilombolas sobre o cuidado em saúde. Método: consiste em um estudo descritivo, qualitativo, realizado entre novembro de 2017 e janeiro de 2018 na comunidade quilombola Abacatal/ Aurá, em Ananindeua, cidade brasileira do estado do Pará. Participaram 30 mulheres que vivenciavam o cuidado em saúde. Os dados foram produzidos a partir de entrevistas individuais, submetidos à Análise Temática e discutidos à luz da Teoria das Representações Sociais. Resultados: as representações foram organizadas em três dimensões: afetiva, a mais representativa, em que se ancoraram relações de afeto e sentimentos; social, na qual o cuidado foi apreendido como prática inerente à mulher; e biológica, sendo o cuidado compreendido como cuidados gerais de prevenção e tratamento de doenças. Conclusões e implicações para a prática: as representações do cuidado em saúde evidenciaram forte carga afetiva, denotando um sentido de preservação da vida e do ambiente, identificando com o cuidado o gênero feminino e, ainda que de forma minoritária revelando hábitos e ações higienistas referendadas pelo discurso técnico-científico entrelaçado com os saberes tradicionais. Esses aspectos trazem singularidades que devem ser consideradas pela enfermagem, uma vez que esta atua com o cuidado integral à saúde dos indivíduos e seus respectivos grupos e (re)produz esse cuidado.

Palavras-chave: Enfermagem; Grupo com Ancestrais do Continente Africano; Mulheres; Psicologia Social; Saúde das Minorias Étnicas.

\begin{abstract}
Objective: To analyze the social representations of quilombola women about health care. Method: descriptive, qualitative study, carried out between November 2017 and January 2018 in the Quilombola community Abacatal/Aurá, in Ananindeua, Pará Brazil. Thirty women who experience health care participated. Data were produced through individual interviews, submitted to Thematic Analysis and discussed on focus by Social Representations Theory. Results: representations were organized into three dimensions: Affective, the most representative, where relationships of affection and feelings were anchored; Social, in which care was perceived as a practice inherent to women; and Biological, with care being understood as general care for prevention and treatment of diseases. Conclusions and implications for practice: the representations of health care showed a strong affective charge, denoting a preservation sense of life and environment, referred to an identity of care for the female gender and, even though a minority, revealed habits and endorsed hygienist actions by the technical-scientific discourse intertwined with traditional knowledge. These aspects bring singularities that must be considered by nursing, as it acts and (re)produces comprehensive health care for individuals and their respective groups.
\end{abstract}

Keywords: Nursing; African Continental Ancestry Group; Women; Psychology, Social; Health of Ethnic Minorities.

\section{Resumen}

Objetivo: Analizar las representaciones sociales de las mujeres quilombolas sobre el cuidado de la salud. Método: estudio descriptivo, cualitativo, realizado entre noviembre de 2017 y enero de 2018 en la comunidad quilombola Abacatal/Aurá, en Ananindeua, Pará, Brasil. Participaron treinta mujeres que vivencian el cuidado en salud. Los datos fueron producidos a través de entrevistas individuales, sometidos al Análisis Temático y discutidos bajo el prisma de la Teoría de las Representaciones Sociales. Resultados: las representaciones se organizaron en tres dimensiones: afectiva, la más representativa, en que se anclaron relaciones de afecto y sentimientos; Social, en la que el cuidado se percibe como una práctica inherente a la mujer; y Biológico, en que se entiende el cuidado como cuidados generales para la prevención y tratamiento de enfermedades. Conclusiones e implicaciones para la práctica: las representaciones del cuidado en la salud mostraron una fuerte carga afectiva al expresar un sentido de preservación de la vida y del ambiente, al atenerse a una identidad de cuidado para el género femenino y, aunque de forma menos expresiva, al revelar hábitos y acciones higienistas refrendadas por el discurso técnico-científico entrelazado con los saberes tradicionales. Estos aspectos presentan singularidades que deben ser consideradas por la enfermería, puesto que, actúa y (re)produce la atención integral con la salud para los individuos y sus respectivos grupos.

Palabras clave: Enfermería; Grupo de Ascendencia Continental Africana; Mujeres; Psicología Social; Salud de las Minorías Étnicas.
Autor correspondente:
Ingrid Fabiane Santos da Silva.

E-mail: ingridenfermeir@gmail.com

Recebido em 02/08/2021.

Aprovado em 21/11/2021.

DOI:https://doi.org/10.1590/2177-9465-EAN-2021-0289 


\section{INTRODUÇÃO}

Os quilombos configuraram-se, no decorrer da história brasileira, como territórios de luta e resistência contra o sistema escravocrata, alcançando diversas áreas do território nacional. Atualmente, essas comunidades, oriundas de grupos com ancestrais do continente africano, são consideradas uma forte organização social da população negra que favorece o resgate de sua cultura e sua humanização. Essas comunidades utilizam um modo peculiar de cuidado, pautado em práticas tradicionais de saúde que, historicamente, vêm sendo desenvolvidas e transmitidas às gerações. ${ }^{1}$

O cuidado é um modo de agir que emerge das experiências do cotidiano e do modo específico de vida, prática ligada histórica e culturalmente às mulheres. Esse tipo de cuidado, o qual envolve valores, costumes, tradições e crenças proporcionados a partir de uma determinada cultura, é definido como cuidado cultural e subsidia a coletividade para a manutenção do bem-estar e o enfrentamento de doenças, de incapacidades e até mesmo da morte..$^{2-4}$

O cuidado em saúde dos grupos populares é um conjunto de ações já estabelecidas na cultura e no cotidiano dos indivíduos e da sua coletividade, ao qual se recorre para a manutenção da saúde, a fim de evitar o adoecimento de si e/ou do outro. Essas práticas são repassadas de geração a geração e têm na mulher sua principal propagadora e praticante, que perpetua essa prática, considerada comum, no seio das comunidades quilombolas. ${ }^{3,4}$ Assim, entende-se que esse cuidado, por guardar características de construção por conhecimentos circulantes entre o grupo, necessita de uma abordagem pela lente da Teoria das Representações Sociais (TRS), desenvolvida e estruturada no âmbito da Psicologia Social. ${ }^{5}$

As representações sociais (RS) são compreendidas como uma forma de conhecimento do universo consensual, diferente daquele produzido pela ciência formal, denominado conhecimento reificado. Apresentam valor simbólico quando orientam um determinado pensamento sobre o objeto de representação e valor prático quando determinam a maneira como se agirá frente a ele. ${ }^{5,6}$

Toda representação é uma forma de conhecimento, entendido como um saber advindo do senso comum, um saber prático, referente à experiência do sujeito, construído e compartilhado em uma sociedade ou um determinado grupo. Essas representações têm por finalidade a construção de uma realidade comum a todos os indivíduos pertencentes a um grupo social, além de intermediarem as relações sociais nas esferas macro (sociedade) e micro (indivíduo), tais como condutas, comunicações, identidades, entre outras. Estabelecem uma relação de simbolização e interpretação com o objeto representado, pois são atribuídos significados e analogias particulares daqueles que o (re)significam. ${ }^{7}$ Para gerar RS, tal objeto deve transpor as esferas sensorial e cognitiva da representação para ser interpretado conscientemente pelo coletivo, o qual não apenas reproduz esse objeto mas também confere a ele novo sentido e significado a partir do universo que circunda a coletividade. ${ }^{5}$
Dessa maneira, entende-se que o cuidado em saúde é objeto de RS para as mulheres quilombolas por apresentar relevância cultural nesse grupo, já que o cuidar é um elemento marcante para o papel social da mulher no contexto dessas populações. Considera-se, também, que os saberes tradicionais sobre saúde representam uma forma de pensamento sobre o objeto, e as práticas populares a ele relacionadas são a conformação desse objeto no cotidiano do grupo, uma vez que são exercitados e postos em prática cotidianamente.

O estudo das RS é uma forma de acesso aos saberes básicos do cotidiano das pessoas. O objetivo prático é compreender e interpretar o mundo que cerca esses sujeitos, pois carregam consigo a marca do pertencimento ao grupo e trazem a sua identidade, sobre a qual incidem a história, o lugar e a função que ocupam na sociedade, além da experiência coletiva e individual vivenciada. ${ }^{8}$

Todas essas questões influenciam a maneira de pensar do sujeito, podendo-se considerar que o pensamento não se faz isolado do social. Dessa forma, percebe-se que a concepção de cuidado em saúde perpassa pelo universo consensual das pessoas, visto que cada grupo estabelece uma forma própria de cuidar da sua saúde, adotando práticas que influenciam diretamente a forma como esse cuidado é entendido, efetivado e partilhado no seio da comunidade. Essa concepção é também uma forma de afirmação identitária do grupo. ${ }^{8}$

É relevante investigar as RS sobre o cuidado em saúde de mulheres quilombolas, pois identificam-se escassos estudos na área da saúde e da enfermagem relativos a esse tema. Além disso, entende-se que há necessidade de maior visibilidade para esse grupo, da efetivação de políticas públicas de saúde a ele destinado e de maior inserção da Enfermagem na produção de um cuidado em saúde que considere os saberes e práticas das minorias étnicas para contribuir com a melhoria dos seus indicadores de condições de vida e saúde.

Populações quilombolas têm sido historicamente vulnerabilizadas, e sua situação de saúde reflete as condições sociais, econômicas e políticas nas quais têm sobrevivido. Em geral, os grupos remanescentes de quilombos apresentam alguns dos piores indicadores epidemiológicos nacionais, como prevalência de hipertensão, ${ }^{9-11}$ baixa escolaridade e condições precárias de saneamento. ${ }^{12,13}$ No entanto, ainda há poucos estudos dedicados a esse segmento da população que possam ajudar no planejamento de políticas públicas mais adequadas às suas necessidades. Além disso, destaca-se que, histórica e socialmente, as mulheres assumem o papel de cuidadora do lar e da família. ${ }^{14}$

Nesse contexto, o objetivo deste estudo é analisar as RS de mulheres quilombolas sobre o cuidado em saúde.

\section{MÉTODO}

Este é um estudo descritivo com abordagem qualitativa, tendo como suporte teórico a vertente processual da TRS. ${ }^{5} \mathrm{~A}$ pesquisa foi baseada nos critérios consolidados para relato de estudos qualitativos (COREQ). ${ }^{15,16}$ 
A pesquisa atendeu à Resolução 466/2012 do Conselho Nacional de Saúde (CNS) e obteve autorização institucional da Secretaria Municipal de Saúde de Ananindeua/Pará e da Associação dos Moradores e Produtores Quilombolas de Abacatal/Aurá (AMPQUA). O projeto foi aprovado pelo Comitê de Ética em Pesquisa do curso de Enfermagem da Universidade do Estado do Pará.

O estudo foi realizado na comunidade quilombola Abacatal/ Aurá, certificada e reconhecida como território quilombola em 1999 pelo Instituto de Terras do Pará (ITERPA). A comunidade está localizada no município de Ananindeua, situada a, aproximadamente, oito quilômetros do seu centro administrativo e inserida na região metropolitana de Belém, capital do Estado do Pará, na região norte do Brasil.

A comunidade foi constituída a partir da relação entre o dono do engenho, Conde Coma Melo, com uma de suas escravas, chamada Olímpia, em meados no século XVIII. Dessa união, foram geradas três filhas: Maria do Ó Rosa de Moraes, Maria Filistina Barbosa e Maria Margarida Rodrigues da Costa, as quais originaram os troncos familiares "Rosa", "Barbosa" e "Costa" da comunidade. O território do antigo engenho foi deixado como herança para as filhas do Conde com a escrava, e, até hoje, os descendentes dessas famílias são conhecidos como "herdeiros" pela ligação histórica e consanguínea entre a escrava e o Conde. ${ }^{17}$

Estabeleceu-se contato prévio com a comunidade em março de 2017, a partir de uma ação de saúde promovida pela Secretaria de Saúde de Ananindeua (SESAU). Naquele momento, articulou-se, com a líder comunitária, conversa inicial sobre o projeto de pesquisa e o interesse de executá-lo na comunidade.

A pesquisa foi conduzida pela autora principal deste artigo, sendo a abordagem das participantes mediada pela líder, a qual fez indicação prévia das famílias e das mulheres por meio de listagem nominal. Assim, colaborou como a informante-chave que, em situações de pesquisa, pode ajudar os pesquisadores por meio de informações importantes e precisas sobre um determinado grupo, funcionando como elo entre esse grupo e os pesquisadores. ${ }^{18}$

As participantes foram abordadas em seus domicílios e convidadas a participar da pesquisa, ocasião em que foram explicados os objetivos, riscos e benefícios, bem como procedeuse à leitura do Termo de Consentimento Livre e Esclarecido (TCLE) e à assinatura, a qual ratificava a concordância delas em participar do estudo. As entrevistas foram gravadas mediante consentimento prévio e identificadas com código alfanumérico, utilizando a letra $\mathrm{M}$, de "mulher", seguida de um número conforme a ordem da realização das entrevistas, com vistas à preservação da identidade das participantes.

Participaram mulheres quilombolas que atenderam aos critérios de inclusão adotados: adultas, com faixa etária acima de 18 anos, residentes na comunidade de Abacatal/Aurá e descendentes das três famílias originárias da comunidade — "Rosa", "Costa" e "Barbosa", as chamadas herdeiras. O universo de potenciais participantes era de 62 mulheres, entre as quais 32 satisfaziam aos critérios de inclusão, e 30 aceitaram e compuseram o estudo, representando $48,38 \%$ do universo total. Duas foram excluídas por não terem sido localizadas em seus domicílios, após três tentativas. Considerou-se também o critério de saturação, tendo em vista que, além de os depoimentos não trazerem novos aspectos para gerar análise diferenciada, a literatura científica prevê uma saturação, em pesquisas qualitativas, entre 20 e 30 entrevistas. ${ }^{19,20}$

Realizaram-se entrevistas individuais com a utilização de roteiro semiestruturado, cujas questões exploraram o objeto de estudo, tendo como temas orientadores os significados do cuidado em geral e do cuidado em saúde, além das práticas desses cuidados e de quem os realiza. Buscaram-se, também, dados para estabelecer a pertença grupal das mulheres, como escolaridade, religião, estado civil e renda. As entrevistas foram realizadas nos finais de semana de novembro de 2017 a janeiro de 2018, momentos em que a pesquisadora foi acolhida na comunidade, hospedando-se na casa de uma moradora durante toda a etapa de produção dos dados e convivendo com a rotina da comunidade. Dessa forma, um total de 28 entrevistas foram realizadas nos domicílios das participantes, em ambiente tranquilo e livre de ruído, e apenas duas na sede da AMPQUA, por escolha delas. Cada entrevista teve em média 40 a 50 minutos de duração.

Aos dados sociodemográficos aplicou-se a estatística simples e percentual, e ao corpus das entrevistas a técnica de análise de conteúdo temática, seguindo-se suas três fases: préanálise, exploração do material e tratamento dos resultados. ${ }^{21}$ Inicialmente, as entrevistas foram transcritas para constituir o corpus submetido à leitura prévia. Nas fases de exploração do material e de tratamento dos resultados, fez-se leitura cuidadosa dos depoimentos, e montaram-se quadros analíticos no software Microsoft Office Excel 2007, constituídos pelas perguntas do instrumento na coluna horizontal e pelas unidades de registro extraídas dos depoimentos de cada participante na coluna vertical.

Em análise horizontal, mapeou-se, em conjunto, o conteúdo das respostas de todas as participantes para cada pergunta formulada, identificando temas comuns. Em análise vertical, identificaram-se os temas em ocorrência e co-ocorrência nos depoimentos individuais ao conjunto de perguntas. Ao todo, foram registradas 390 unidades de contextos em que se destacaram temas, expressões e metáforas, de forma a identificar os conteúdos que fizessem sentido na elaboração das RS das mulheres sobre o objeto.

Mediante os temas identificados, as categorias foram organizadas em três dimensões que abrigaram as ideias e os pensamentos das mulheres. A primeira é a dimensão afetiva do cuidado, a segunda a dimensão social, e a terceira a dimensão biológica. A organização dessas dimensões deu-se de maneira convergente, nunca de forma fragmentada. À medida que as mulheres expressavam seus saberes sobre o cuidado em saúde, organizava-se a dimensão à qual os temas extraídos dos depoimentos estariam associados a partir de sua ocorrência e sua co-ocorrência. A incidência dos temas nas categorias foi indicada pelo número absoluto e percentual correspondente de participantes que os abordaram em seus depoimentos. Dessa 
maneira, cada tema e dimensão levou em consideração o número total de mulheres, uma vez que se identificou a presença de temas relativos a mais de uma dimensão em um mesmo depoimento. Assim, os percentuais que se somam nas três dimensões podem ultrapassar $100 \%$.

\section{RESULTADOS}

Quanto ao perfil, predominou a faixa etária de 18 a 29 anos $(9 / 30 \%)$, revelando participantes jovens, mais da metade estando em união estável (17/56,6\%) e sendo mães (27/90\%), com média de 1 a 2 filhos (14/46,6\%). No quesito religião, predominou o catolicismo (26/86,6\%), e, na escolaridade, o Ensino Fundamental incompleto (9/30\%). Metade (15/50\%) declarou-se agricultora/ produtora rural, com renda média pessoal e familiar menor ou igual a um salário-mínimo.

No contexto da dimensão afetiva, a maior parte (20/66,6\%) referiu-se ao cuidado em saúde com uma conjuntura de sentimentos. Assim, palavras como "amor", "respeito", "zelo", "atenção", "proteção" e "carinho" foram verbalizadas por elas como sinônimos desse cuidado, seja com familiares e com não familiares, seja até mesmo com o ambiente que as cerca:

\section{[...] Cuidar pra mim é o mesmo que preservar, amar [...]} é proteger acima de tudo (M6).

[...] Proteger, significa pra mim [...], ter o cuidado significa amar, [...] porque, se tu amas, tu cuidas, se não tem o amor, se não tem o respeito, não tem o cuidado [...] pra mim o cuidado significa amor e o respeito (M8).

[...] quando a gente fala em cuidar, eu acho que é quando a gente gosta das pessoas, a gente quer que as pessoas estejam bem, então a gente vai cuidar pra que elas fiquem bem, tanto faz as pessoas serem da família ou não, uma coisa que a gente goste a gente cuida [...] então eu acho que cuidado é isso, é gostar, é amar (M19).

[...] Cuidado assim de uma forma geral, de limpeza das coisas. Eu gosto das minhas coisas bem limpas. $A$ gente tem que ter muito cuidado com o meio ambiente também. Eu não gosto também que estejam derrubando (as árvores) para destruir a natureza, tem que preservar o meio ambiente. Eu tenho isso como cuidado também (M11).

Na dimensão social (12/40\%), demarca-se a responsabilidade que elas sinalizaram ter no cuidado consigo e com outros, como um dever, assumido pela mulher, de cuidar da família e dos filhos e de ser uma boa mãe. Isso evidencia que a concepção do cuidado em saúde está paralelamente ligada ao papel social da mulher na sociedade, vista como aquela detentora da responsabilidade de cuidar:

[...] Cuidar da família, da casa, dos netos também. Do serviço de casa, fazer compras, tudo isso eu faço (M22).
[...] Cuidar dos meus filhos, cuidar da saúde, cuidar de casa (M4).

[...] Pra mim cuidar é ser uma boa mãe e estar atenta 24 horas com eles (M6).

Já a dimensão biológica (8/26,6\%) do cuidado em saúde pôde ser apreendida nos depoimentos quando estes reportaram preocupação com alimentação, cuidados de prevenção ao adoecimento, cuidados de higiene e as necessidades de consultar um profissional da saúde, tomar medicamentos e manter a saúde de si mesmas e dos outros:

[...] Significa manter um cuidado com a saúde regularmente, é verificando o estado de saúde consultando um especialista na área e tendo informações de prevenções, como que eu posso me prevenir (M1).

[...] Evitar que as crianças estejam metendo a mão suja na boca, estejam comendo coisas que vá fazer mal para saúde, tomar banho diariamente, escovar os dentes, viver sempre limpo em um ambiente saudável, não deixar a criança correr descalça pelo chão (M10).

[...] Cuidar da saúde é a prevenção, é se prevenir das doenças [...] cuidado tá em você, nas prevenções, prevenir, fazer os exames sempre (M12).

\section{DISCUSSÃO}

A dimensão afetiva foi a categoria de destaque nas falas das participantes, apresentando maior densidade de resultados e possibilitando acessar as conotações subjetivas que a representação do cuidado tem para as mulheres. Elas são dotadas de singularidades e subjetividades advindas da sua trajetória de vida, da sua experiência cotidiana, da sua cosmovisão e da sua historicidade, sendo estas (co)produtoras da realidade partilhada junto ao grupo social e individualmente. Destaca-se que a história, a posição do sujeito no grupo e os afetos colaboram para a (con)formação do objeto social. Para tal, este deve ter relevância para o grupo que o representa. ${ }^{6}$

A TRS considera o sujeito ativo, capaz de fazer escolhas e de organizar e reorganizar imagens plenas de representações mediante situações que demandam a tomada de atitude ou mesmo a emissão de concepções. ${ }^{22}$ Dessa forma, as mulheres construíram suas representações sobre o cuidado a partir da ancoragem em sentimentos denotadores de afetividade, tais como amor, respeito, zelo, carinho, proteção e preservação. São esses sentimentos que dão significado ao objeto, porque o cuidar é entendido como as atitudes e expressões de amor e carinho, como já evidenciado por outro estudo sobre as RS do cuidado, no qual o núcleo central da representação era composto por amor, carinho e paciência. ${ }^{23}$

Os afetos predominaram na construção das RS e estão apoiados na memória e na experiência, pois o objeto é provocativo 
e convida a falar sobre ele; ao falar sobre o objeto, fala-se de si. ${ }^{8}$ É com base na dimensão afetiva que se estabelecem as escolhas e definem-se as práticas. Importa reconhecer, então, o papel das emoções e dos afetos no funcionamento das representações, em razão de a inserção do repertório, advindo das representações sobre o cuidado, ocorrer justamente no cotidiano das mulheres. Além disso, suas práticas dão-se a partir de sua identidade social e da forma como se sentem frente ao cuidado, emaranhando conhecimento e afeto de forma que estes se influenciam mutuamente, ou seja, o sujeito (re)inventa-se à medida que (re)apresenta e (re)elabora o objeto, produzindo, dessa maneira, subjetividades. ${ }^{8,22}$

A carga afetiva, acarretada pelo objeto, incide diretamente na produção da representação social, em todos os seus processos e etapas, inclusive nas demais dimensões. Isso se deve ao movimento ser constante e retroalimentar, uma vez que o afeto é percebido como um veículo promotor de conhecimento. ${ }^{8}$ Os afetos também são elementos com os quais as mulheres quilombolas reafirmam-se e fortalecem-se, permitindo a elas vivenciar saúde e bem-estar. ${ }^{24}$

Nota-se que, para além da implicação afetiva entre pessoa e pessoa, essa dimensão alcança outros campos e abrange também o meio em que se vive, acontecendo uma relação entre sujeito e ambiente, expressa nas falas pela palavra "preservação", a qual está associada ao cuidado. Outras participantes indicaram que o cuidado envolve manter o ambiente limpo, viver em um ambiente agradável e zelar pelo seu entorno, seja a casa, o terreno ou mesmo a comunidade.

Dessa forma, quando o cuidado em saúde também é representado pela manutenção da paisagem natural do lugar, observa-se a existência de uma transposição da mulher para o ambiente, em virtude de ela fazer parte dele, e a consciência de que cuidar do ambiente implica cuidar de si e dos demais os quais, assim como ela, compõem o cenário local. O entendimento desse pertencimento, do "eu ambiente", também faz acontecer o cuidado em saúde. Para as quilombolas, é o ambiente o lugar onde se encontram a diversidade e as possibilidades de exploração dos recursos vegetais e animais e das ervas e plantas medicinais, que também são utilizadas no cuidado em saúde e, por isso, fazem parte da dimensão afetiva em que se constrói a representação desse cuidado.

Essa dimensão é a mais representativa e torna-se mais significativa em conjunto com as demais dimensões, evidenciando que, para essas mulheres, o cuidado sustenta-se muito mais nas suas relações e na sua interação com tudo que as move e que as cerca. Isso repercute diretamente tanto nos cuidados demandados por elas quanto nos cuidados entendidos como necessários para toda a família e para a comunidade. Ainda, a dimensão afetiva confere a característica mais singular à representação social do cuidado em saúde para o grupo.

Já na dimensão social, destaca-se que o cuidado é considerado incumbência feminina, sendo identificado pelas mulheres quilombolas como a realização de um dever, de uma obrigação que favorece o elo e o apego na relação com quem se cuida. Essa identificação do gênero feminino com o cuidado pode ser explicada a partir da contextualização histórica e cultural das relações familiares, dentro da qual à mulher eram designadas as funções de reprodução e cuidado da prole. ${ }^{25,26}$

Em estudo realizado com mulheres quilombolas com objetivo de conhecer os significados, os sentimentos e as práticas de cuidado, encontraram-se resultados semelhantes, já que o significado atribuído ao cuidado em saúde estava relacionado às atividades cotidianas executadas pelas mulheres no contexto familiar. Destacou-se, ainda, a possibilidade de essas contribuírem para o desempenho de tarefas não apenas nesse cenário doméstico, mas também nas atividades voltadas para o bem-estar da comunidade como um todo. ${ }^{4}$

Em consonância, um estudo que investigou a formação social dos papéis de pai e de mãe identificou que as mães assumiam o papel principal na prestação de cuidados aos filhos, enquanto, para os pais, o cuidado era função secundária, pois eles eram vistos como apoiadores/auxiliadores ou provedores materiais da família. Essas questões ancoram-se nas ideias que compreendem a maternidade como sinônimo de cuidado, ao tempo que reforçam e legitimam o cuidado como atribuição feminina. ${ }^{10,27}$

No que diz respeito às tarefas domésticas em si, reportadas nos depoimentos, os achados são semelhantes aos de um estudo que buscou as RS de homens e mulheres sobre o trabalho feminino na comunidade Cajueiro, em Bragança, cidade do estado do Pará. Nele, o trabalho feminino foi associado às atividades domésticas, como limpeza da casa e do quintal, criação de animais e cuidados com as plantas, os idosos, as crianças e os doentes da comunidade, além de compras e lavagem de roupa. Em diversos segmentos rurais da Amazônia, os afazeres relacionados à casa são considerados práticas femininas. Uma vez que a mulher é a "dona de casa", essas práticas são consideradas "naturais" e pertencem à esfera privada, ao passo que ao homem é conferido o espaço público. ${ }^{28}$

A argumentação do cuidado expresso nessa dimensão social não exclui a presença da afetividade em razão de o cuidado prestado pela mulher no contexto familiar ser cercado pelos afetos, sobretudo pela condição da maternidade. Nos resultados aqui alcançados, assim como nos de outros autores, ${ }^{27}$ é impresso ao cuidado uma conotação exclusivamente feminina. Por isso, ele deve ser designado à mulher/mãe, concepção que se ancora em memórias engendradas na sociedade, além de veiculadas e propagadas às demais mulheres.

De tal modo, se o cuidado em saúde incorpora uma dimensão social ao ser vinculado ao papel social da mulher, é porque essas RS estão ligadas às formas anteriores de se pensar o objeto. No universo quilombola, devido à ausência de outras formas de preservação histórica, a oralidade e as memórias operam como formas de resistência e cumprem a função social de afirmar uma identidade cultural frente à massificação global de culturas diferentes. Recordar e resistir funcionam como elementos de representação que necessitam ser reconstituídos nas práticas de ação, atuação e pertencimento, pois são resultado de variações 
ou perpetrações ocorridas ao longo do tempo, sendo transmitidas ou impostas às gerações e influenciando diretamente na maneira de pensar e representar o objeto. ${ }^{6,29}$

$A$ variação das $R S$ deve-se à inserção social dos indivíduos na coletividade. Dessa forma, os seus processos formadores não derivam de apenas um único campo representacional, ou seja, o coletivo não sobressai ao individual ou vice-versa. Essa lógica foi superada pela TRS.

Atualmente, o papel social das mulheres na família e na sociedade transformou-se, porque novos papéis foram atribuídos a elas (envolvendo trabalho, política, economia, entre outros) e porque a concepção de família nuclear composta exclusivamente de pai, mãe e filhos foi modificada. ${ }^{30}$ Apesar disso, pôde-se constatar que, para as mulheres quilombolas de Abacatal/Aurá, esse contexto pouco foi alterado.

Fazer essa explicação à luz da TRS impõe lembrar que as RS estão inseridas em um contexto pré-existente e dependem das tradições, dos valores e das crenças associadas ao objeto representado. Nesse sentido, o objeto pode ser reincorporado às explicações familiares ao indivíduo e ao seu grupo, sendo composição e ao mesmo tempo troca, imprescindível para a construção de pensamentos consensuais e do compartilhamento destes com o grupo social, os quais possibilitarão pertencimento social - no caso, ser mulher e quilombola. ${ }^{6}$

A dimensão social está ancorada na representação do cuidado como atribuição do gênero feminino, conectando-se ao estereótipo da mulher cuidadora nata e estando fortemente ligado à esfera familiar privada. Dessa forma, o cuidado continua atrelado à mulher e vinculado ao ambiente doméstico e familiar, como foi possível evidenciar nessa dimensão. Destaca-se, ainda, que essa concepção, apesar das conquistas femininas na sociedade, não apenas é predominante no contexto quilombola mas também é partilhada na sociedade como um todo.

Por fim, no que diz respeito à dimensão biológica, um estudo ${ }^{31}$ realizado com mulheres de uma comunidade quilombola da região Sul do Brasil identificou que os significados do cuidado estavam estritamente vinculados a menções de cunho biologicista, com fins de manutenção ou geração de saúde para garantir as demais atividades do cotidiano. Por sua vez, nos achados desta pesquisa, essa dimensão foi minoritária, sobressaindo-se as questões afetiva e relacional do cuidado.

Outro estudo demonstrou que as representações do cuidado em saúde para mulheres e homens idosos estavam fortemente associadas aos aspectos biológicos do objeto. Este foi referido pelas mulheres por meio de atos e ações permanentes que gerem saúde e de obediência a normas prescritivas orientadas pelo médico, como higiene, alimentação e repouso, entre outras. ${ }^{32}$ As concepções pautadas nesses elementos biológicos revelam que essa representação do cuidado em saúde, ancorada em hábitos e ações de cunho higienista, foi disseminada ao longo do tempo pelo modelo biomédico, apesar de, hoje, a concepção de cuidado em saúde ter evoluído para práticas integrais e coletivas. ${ }^{33,34}$

Essas concepções são semelhantes às evidenciadas por esta pesquisa, todavia as representações das mulheres quilombolas sobre o cuidado em saúde, no presente estudo, adquiriram conotações que extrapolaram o campo exclusivo da saúde, sendo o aspecto biológico do objeto apenas uma das dimensões que compõem a representação dele. Vale refletir se essas diferenças encontradas nos estudos podem estar relacionadas às pertenças sociais dessas mulheres, considerando-se que os aspectos do cotidiano urbano e os do rural podem influenciar nessas RS.

Nessa dimensão biológica, identificou-se, nos depoimentos, que há uma predominância do discurso reificado para construir as representações do cuidado em saúde, já que os conhecimentos aqui expostos dizem respeito ao campo das ciências biológicas e da saúde, com a evocação de normas prescritivas que orientam como cuidar da saúde e manter-se saudável. Ao universo reificado pertencem os saberes advindos das Ciências, as quais buscam dar explicações imparciais, baseadas na lógica matemática quantificável da experimentação. Entretanto, as RS abordam o universo consensual, ${ }^{6}$ universo este que é o lócus da familiaridade. Nesse caso, pode-se dizer que a concepção reificada do cuidado em saúde foi ressignificada em senso comum, porque se percebeu claramente uma transposição do saber reificado para o consensual, de forma que o objeto é (re) apresentado e renovado, sendo-lhe atribuídas novas significações.

Importa ressaltar que a transição de campos de saberes (do reificado para o senso comum) acontece por meio das crenças, dos mitos e até mesmo dos saberes populares. Ainda, estes não apresentam níveis de hierarquia ou graus de importância que possibilitem a sobreposição de um a outro. Ao contrário, tais saberes sinalizam conhecimentos e finalidades e pertencem a campos distintos, contudo indicam pluralidades na forma de pensar e atendem ao contexto em que os saberes são produzidos. ${ }^{8}$

Dessa forma, o cuidado em saúde, quando investigado pela TRS, adquire status de fenômeno psicossocial ao agrupar saberes reificados, pois são produzidos pelo conhecimento científico, e demarca-os como objeto de conhecimento e prática no campo da saúde. Ademais, pela via consensual, esse campo manifesta modos de ser e agir provenientes das culturas, com atitudes próprias e particulares de lidar com o corpo e com a saúde. ${ }^{35}$

Em tal perspectiva, pode-se dizer que as mulheres quilombolas, quando constroem e expressam seus pensamentos sobre cuidado em saúde, recorrem aos dois campos que influenciam a conformação do objeto: o saber reificado e o consensual. Essa representação, vinculada ao contexto dos saberes, mostrou-se relevante porque ela desvelou formas distintas de pensar e conceber o objeto, mas essas formas convergem para práticas semelhantes que puderam ser organizadas por meio das dimensões aqui abordadas.

Entende-se que conhecer esses contextos e essas representações é de suma importância para a organização de cuidados que atendam às reais necessidades e especificidades dessas populações, considerando as dimensões cultural e representacional adquiridas pelo cuidado em suas vidas e o universo de saberes e representações que os circundam. Neste estudo, os aspectos da representação do cuidado na dimensão biológica revelaram-se diminutos, bem como as atitudes e práticas 
que derivam dela. A constituição das RS pelas três dimensões no contexto quilombola implica um cuidado em saúde complexo, cercado de subjetividade e identidade sociocultural próprias do universo quilombola, mostrando interconexões entre o saber tradicional e o saber reificado.

Nesse sentindo, cabe refletir sobre o tipo de cuidado prestado, bem como sobre a organização do serviço de saúde e sobre como este se apresenta para o público em questão. A razão disso é a demanda por cuidados que expressem um caráter afetivo e relacional, a qual sobressaiu às demandas biológicas, e os serviços de saúde estarem majoritariamente organizados pelo modelo biomédico, no qual toda clínica é voltada para o diagnóstico de situações de saúde específicas, como os sintomas objetivados no corpo físico do indivíduo.

\section{CONSIDERAÇÕES FINAIS E IMPLICAÇÕES PARA A PRÁTICA}

As RS do cuidado em saúde pelas mulheres quilombolas evidenciam uma compreensão abrangente desse tipo de cuidado, para além de atividades pontuais. Abarcam qualidades de relações humanas, sentidos de preservação da vida, expressiva identificação do cuidado com o gênero feminino, assim como hábitos e ações higienistas referendados pelo modelo biomédico, o que mostra forte carga do discurso técnico-científico entrelaçado com os saberes tradicionais.

Para as mulheres de Abacatal/Aurá, há a demanda por um cuidado com base na construção de vínculos, no afeto e na escuta, pois estes são os pilares do cuidado em saúde e permeiam todo o conjunto de representações estabelecido neste trabalho. Esses aspectos trazem singularidades que devem ser consideradas pelos profissionais da saúde e, sobretudo, pelos profissionais de enfermagem, uma vez que essa área, em particular, atua com o cuidado integral à saúde dos indivíduos e seus respectivos grupos e (re)produz esse cuidado.

Considerando que este estudo foi desenvolvido em apenas uma comunidade quilombola, as representações aqui discutidas podem não ser passíveis de generalização, o que se configura como uma limitação do estudo. As formas de representar os objetos sociais dizem respeito ao universo dos grupos que constroem tais representações a partir de suas experiências práticas no cotidiano e são particulares a cada grupo. Entretanto, as conexões com realidades de outras comunidades quilombolas ou mesmo com situações análogas em outros grupos podem ser passíveis de investigação. Entende-se que esses achados podem contribuir para melhor compreensão do universo das representações do cuidado no grupo estudado e estimular a reflexão em estudos similares e/ou sobre outras comunidades que partilham das mesmas características.

\section{FINANCIAMENTO}

O presente trabalho foi realizado com apoio da Coordenação de Aperfeiçoamento de Pessoal de Nível Superior - Brasil (CAPES) - Código de Financiamento 001.

\section{CONTRIBUIÇÕES DOS AUTORES}

Desenho do estudo. Ingrid Fabiane Santos da Silva. Ivaneide Leal Ataíde Rodrigues.

Coleta ou produção dos dados. Ingrid Fabiane Santos da Silva. Ivaneide Leal Ataíde Rodrigues.

Análise de dados. Ingrid Fabiane Santos da Silva. Ivaneide Leal Ataíde Rodrigues. Laura Maria Vidal Nogueira. Hilton Pereira da Silva. laci Proença Palmeira.

Interpretação dos resultados. Ingrid Fabiane Santos da Silva. Ivaneide Leal Ataíde Rodrigues. Laura Maria Vidal Nogueira. Hilton Pereira da Silva. Iaci Proença Palmeira.

Redação e revisão crítica do manuscrito. Ingrid Fabiane Santos da Silva. Ivaneide Leal Ataíde Rodrigues. Laura Maria Vidal Nogueira. Hilton Pereira da Silva. laci Proença Palmeira.

Aprovação da versão final do artigo. Ingrid Fabiane Santos da Silva. Ivaneide Leal Ataíde Rodrigues. Laura Maria Vidal Nogueira. Hilton Pereira da Silva. Iaci Proença Palmeira.

Responsabilidade por todos os aspectos do conteúdo e a integridade do artigo publicado. Ingrid Fabiane Santos da Silva. Ivaneide Leal Ataíde Rodrigues. Laura Maria Vidal Nogueira. Hilton Pereira da Silva. Iaci Proença Palmeira.

\section{EDITOR ASSOCIADO}

Stela Maris de Mello Padoin (1)

\section{EDITOR CIENTÍFICO}

\author{
Ivone Evangelista-Cabral (1)
}

\section{REFERÊNCIAS}

1. Ministério da Saúde (BR). Política Nacional de Saúde Integral da População Negra: uma política para o SUS [Internet]. $3^{\mathrm{a}}$ ed. Brasília: Editora do Ministério da Saúde; 2017 [citado 2018 jul 5]. Disponíve em: https://bvsms.saude.gov.br/bvs/publicacoes/politica_nacional_ saude_populacao_negra_3d.pdf

2. Prates LA, Possati AB, Timm MS, Cremonese L, Oliveira G, Ressel LB Meanings of health care assigned by quilombola women. Rev Pesqui. 2018;10(3):847-55.

3. Prates LA, Ceccon FG, Alves CN, Wilhelm LA, Demori CC, Silva SC et al. A utilização da técnica de grupo focal: um estudo com mulheres quilombolas. Cad Saude Publica. 2015;31(12):2483-92. http://dx.doi. org/10.1590/0102-311X00006715. PMid:26872225.

4. Prates LA, Possati AB, Timm MS, Bortoli CFC, Bisognin P, Ressel LB Características socioeconômicas e de saúde de um grupo de mulheres de uma comunidade quilombola. Rev Enferm UFPE on line. 2016;10(1):10311. https://doi.org/10.5205/1981-8963-v10i1a10927p103-111-2016.

5. Moscovici SA. Psicanálise, sua imagem e seu público. Petrópolis: Vozes; 2012.

6. Moscovici S. Representações Sociais: investigações em psicologia social. 11ª ed. Petrópolis, RJ: Vozes; 2015.

7. Jodelet D. O movimento de retorno ao sujeito e a abordagem das representações sociais. Soc Estado. 2009;24(3):679-712. http://dx.doi. org/10.1590/S0102-69922009000300004

8. Arruda A. Teoria das representações sociais e ciências sociais: trânsito e atravessamentos. Soc Estado. 2009;24(3):739-66. http://dx.doi. org/10.1590/S0102-69922009000300006

9. Silva HP, Padez C, Moura EA, Filgueiras LA. Obesity, hypertension, social determinants of health and the epidemiologic transition among 
traditional Amazonian populations. Ann Hum Biol. 2016 jul;43(4):371-81. http://dx.doi.org/10.1080/03014460.2016.1197967. PMid:27256926.

10. Pauli S, Bairros FS, Nunes LN, Neutzling MB. Prevalência autorreferida de hipertensão e fatores associados em comunidades quilombolas do Rio Grande do Sul, Brasil. Cien Saude Colet. 2019 set;24(9):3293-303. http://dx.doi.org/10.1590/1413-81232018249.28002017.PMid:31508750.

11. Santos DMS, Prado BS, Oliveira CCDC, Almeida-Santos MA. Prevalence of Systemic Arterial Hypertension in Quilombola Communities, State of Sergipe, Brazil. Arq Bras Cardiol. 2019;113(3):383-90. http://dx.doi. org/10.5935/abc.20190143. PMid:31432977.

12. Freitas IA, Rodrigues ILA, Silva IFS, Nogueira LMV. Perfil sociodemográfico e epidemiológico de uma comunidade quilombola na Amazônia Brasileira. Rev Cuid (Bucaramanga). 2018;9(2):2187-200. http://dx.doi. org/10.15649/cuidarte.v9i2.521.

13. Cardoso CS, De Melo LO, Freitas DA. Condições de saúde nas comunidades quilombolas. Rev Enferm UFPE on line. 2018;12(4):1037-45. http://dx.doi.org/10.5205/1981-8963-v12i4a110258p1037-1045-2018.

14. Hedler HC, Faleiros VP, Santos MJS, Almeida MAA. Representação social do cuidado e do cuidador familiar do idoso. Rev Katálysis. 2016;19(1):143-53. http://dx.doi.org/10.1590/1414-49802016.00100015.

15. Tong A, Sainsbury P, Craig J. Consolidated criteria for reporting qualitative research (COREQ): a 32-item checklist for interviews and focus groups. Int J Qual Health Care. 2007;19(6):349-57. http://dx.doi.org/10.1093/ intqhc/mzm042. PMid:17872937.

16. Souza VR, Marziale MH, Silva GT, Nascimento PL. Tradução e validação para a língua portuguesa e avaliação do guia COREQ. Acta Paul Enferm. 2021;34:eAPE02631. http://dx.doi.org/10.37689/acta-ape/2021AO02631.

17. Marin REA, Castro EMR. No caminho de Pedras de Abacatal: experiência social de grupos negros no Pará. $2^{\mathrm{a}}$ ed. Belém: NAEA/UFPA; 2004.

18. Jaccoud M, Mayer R. A observação direta e a pesquisa qualitativa. In: Poupart J, Deslauriers J-P, Groulx L-H, Laperriere A, Mayer R, Pires Á. A pesquisa qualitativa: enfoques epistemológicos e metodológicos. $4^{\text {a }}$ ed. Petrópolis: Vozes; 2014.

19. Saunders B, Sim J, Kingstone T, Baker S, Waterfield J, Bartlam B et al. Saturation in qualitative research: exploring its conceptualization and operationalization. Qual Quant. 2018;52(4):1893-907. http://dx.doi. org/10.1007/s11135-017-0574-8. PMid:29937585.

20. Minayo MCS. Amostragem e saturação em pesquisa qualitativa: consensos e controvérsias. Rev Pesq Qualit. [Internet]. 2017; [citado 2020 mar 17];5(7):1-12. Disponível em: https://editora.sepq.org.br/ index.php/rpq/article/view/82/59

21. Bardin L. Análise de conteúdo. São Paulo: Edições 70; 2016.

22. Pombo-de-Barros CF, Arruda AMS. Afetos e representações sociais: contribuições de um diálogo transdisciplinar. Psicol. 2010;26(2):351-6. http://dx.doi.org/10.1590/S0102-37722010000200017.
23. Hedler HC, Faleiros VP, Santos MJS, Almeida MAA. Representação social do cuidado e do cuidador familiar do idoso. Rev Katálysis. 2016;19(1):143-53. http://dx.doi.org/10.1590/1414-49802016.00100015.

24. Durand MK, Heidemann ITSB. Mulheres quilombolas e o itinerário de pesquisa de Paulo Freire. Texto Contexto Enferm. 2020;29:e20180270. http://dx.doi.org/10.1590/1980-265x-tce-2018-0270.

25. Ariès P. História Social da Criança e da Família. $2^{\underline{a}}$ ed. Rio de Janeiro: LTC; 2017. E-book.

26. Meira EC, Reis LA, Gonçalves LHT, Rodrigues VP, Philipp RR. Vivências de mulheres cuidadoras de pessoas idosas dependentes: orientação de gênero para o cuidado. Esc Anna Nery. 2017;21(2):e20170046. http://dx.doi.org/10.5935/1414-8145.20170046.

27. Martins CA, Abreu WJCP, Figueiredo MCAB. Tornar-se pai e mãe: um papel socialmente construído. Referência (Coimbra). 2014;IV(2):12131. http://dx.doi.org/10.12707/RIII1394.

28. Araújo MEA, Silva MT, Andrade KRC, GalvãoTF, Pereira MG. Prevalência de utilização de serviços de saúde no Brasil: revisão sistemática e metanálise. Epidemiol Serv Saude. 2017;26(3):589-604.PMid:28977183.

29. Valetim RPF. A saúde entre o minoritário e o global: questões identitárias entre mulheres quilombolas. Psicol Saber Soc. 2016;5(1):68-77. https:// doi.org/10.12957/psi.saber.soc.2016.18926.

30. Borsa JC, Nunes MLT. Aspectos psicossociais da parentalidade: o pape de homens e mulheres na família nuclear. Psicol Argum. [Internet]. 2011; [citado 2020 mar 17];29(64):31-9. Disponível em: https://periodicos. pucpr.br/index.php/psicologiaargumento/article/view/19835/19141

31. Prates LA, Possati AB, Timm MS, Cremonese L, Oliveira G, Ressel LB. Meanings of Health Care Assigned by Quilombola Women. Rev Pesqui (Univ Fed Estado Rio J. Online). 2018;10(3):847-55. http:// dx.doi.org/10.9789/2175-5361.2018.v10i3.847-855.

32. Silva SPC, Menandro MCS. Social representations of health and care for elderly men and women. Saude Soc. 2014;23(2):626-40. http:// dx.doi.org/10.1590/S0104-12902014000200022.

33. Silva ICN, Santos MVS, Campos LCM, Silva DO, Porcino CA, Oliveira JF. Representações sociais do cuidado em saúde de pessoas em situação de rua. Rev Esc Enferm USP. 2018;52:e03314. http://dx.doi. org/10.1590/s1980-220x2017023703314. PMid:29846489.

34. Santos El, Alves YR, Gomes AMT, Silva ACSS, Mota DB, Almeida EA. Social representations of nurses' professional autonomy among non nursing health personnel. Online Braz J Nurs. 2016;15(2):146-56. https://doi.org/10.17665/1676-4285.20165294.

35. Ferreira MA. Teoria das Representações Sociais e Contribuições para as Pesquisas do Cuidado em Saúde e de Enfermagem. Esc Anna Nery. 2016;20(2):214-5. https://doi.org/10.5935/1414-8145.20160028.

\footnotetext{
a Artigo extraído da dissertação de mestrado com o título "Representações sociais de mulheres quilombolas sobre o cuidado em saúde" de autoria de Ingrid Fabiane Santos da Silva sob a orientação da Dra. Ivaneide Leal Ataíde Rodrigues. Programa de Pós-Graduação em Enfermagem Associado UEPA/UFAM. Data da defesa 27 de agosto de 2018.
} 